\title{
Da marginalidade ao mainstream: reflexões sobre o MMA (Artes Marciais Mistas) e as sociedades capitalistas contemporâneas
}

\author{
Fábio de Lima Alvarez e José Carlos Marques
}

\section{Resumo}

0 presente artigo tem como objetivo discutir a íntima relação entre as principais características das sociedades capitalistas contemporâneas com um dos esportes/espetáculos que ganha cada vez mais espaço não apenas na mídia brasileira como na mídia internacional: o MMA (sigla em inglês para Artes Marciais Mistas). Para muito além de seu aspecto mais prontamente identificável - 0 da violência, ou agressividade -, este esporte/ espetáculo é bastante paradigmático, pois encarna uma série de valores políticos, econômicos e culturais amplamente valorizados na atual fase de desenvolvimento das sociedades capitalistas, caracterizada majoritariamente pela expansão dos fluxos de informação e mercadorias em nível global, impulsionados principalmente pelo desenvolvimento de novas tecnologias comunicacionais.

\section{Palavras-Chave}

Esportes. Comunicação. MMA. Globalização.

Fábio de Lima Alvarez | fusa_fabio@yahoo.com.br Graduado em Comunicação Social - Habilitação em Jornalismo - Universidade Estadual Paulista Júlio de Mesquita Filho (Unesp), Campus de Bauru. Mestrando em Comunicação da Faculdade de Arquitetura, Artes e Comunicação (FAAC) da Unesp. Bolsista da Coordenação de Aperfeiçoamento de Pessoal de Nível Superior (Capes).

José Carlos Marques I zeca.marques@faac.unesp.br Doutor em Ciências da Comunicação pela Universidade de São Paulo (USP). Docente do Programa de Pós-Graduação em Comunicação da Faculdade de Arquitetura, Artes e Comunicação (FAAC) da Universidade Estadual Paulista Júlio de Mesquita Filho (Unesp), Campus de Bauru.

\section{Introdução}

Os jogos sempre fizeram parte da história humana. Por mais que tentemos negar este fato, é difícil não encontrarmos algum tipo de agrupamento humano que não os tenha desenvolvido. Seja ocupando papeis centrais no desenvolvimento e manutenção de uma determinada comunidade, no caso dos jogos ritualísticos, ou mesmo sem possuir grandes motivos ou causas "nobres" por trás, a exemplo das brincadeiras mais despretensiosas, 0 jogo em suas mais diversas manifestações é, talvez, uma das atividades mais constantes e ininterruptas em toda a história.

Como nos lembra Johan Huizinga (2000), o jogo é uma atividade significante, ou seja, quando se joga, "algo está em jogo", algo que transcende as necessidades imediatas da vida. Em última instância, se desconsiderarmos a carga simbólica atribuída ao ato de jogar (se é que isso é possível), o jogo é algo totalmente descartável; sua existência em nada altera o mundo físico, trata-se de uma atividade não produtiva, que não 
gera riquezas e não muda o estado das coisas. No entanto, apoiando-nos novamente nos dizeres de Huizinga, esta desconexão entre o jogo e a esfera produtiva da vida demonstra justamente que somos muito mais do que simples máquinas biológicas, pois somos capazes de criar mundos "paralelos" e de obter prazer com o ato de jogar. Enfim, o prazer inerente à atividade salienta 0 forte aspecto estético do jogo. 0 jogo nunca é imposto: a única força que o mantém é a vontade de jogar (salvo quando o jogo torna-se elemento cultural central de coesão social, a exemplo dos jogos ritualísticos encontrados aos montes nos mais diversos grupamentos humanos).

Apesar de suas características serem prontamente reconhecíveis por qualquer observador, não existe unanimidade em relação à essência dos jogos: se são atividades que correm em paralelo à vida corrente de determinada sociedade, ou seja, se os jogos refletem as principais características das sociedades que os jogam, ou se, pelo contrário, são nos jogos que se realizam as vontades e anseios que as sociedades negam à maioria de seus membros. São os jogos respostas a um contexto, são os jogos alavancas para determinada conformação social, são os jogos mecanismos de liberação de uma tensão contida que não encontra escape dentro das estruturas sociais?

Fazemos estas perguntas (na verdade, apenas as refazemos, visto que elas são o cerne de grande parte dos estudos voltados para a interpretação do elemento lúdico na cultura) não para tentarmos dar qualquer tipo de resposta, mas apenas para tornar ainda mais evidente a importância de estudos voltados para a compreensão da íntima relação entre os jogos e as sociedades. Chamamos estes questionamentos apenas para adentrarmos na exploração do nosso tema neste artigo, a discussão de algumas das características presentes em um dos jogos mais paradigmáticos da contemporaneidade: as Artes Marciais Mistas, a cada vez mais conhecida sigla MMA (Mixed Martial Arts, em inglês).

\section{0 elemento agonístico na cultura}

Acreditamos que o MMA seja um jogo (na verdade um esporte institucionalizado) que muito nos tem a revelar sobre os princípios norteadores das sociedades capitalistas contemporâneas.

Se iniciamos este texto salientando o caráter paralelo que o jogo possui em relação à vida corrente, reconhecer esta estrutura relativamente autônoma não significa decretar que o jogo não esteja imerso em um contexto mais ampliado propício ao seu florescimento. De Huizinga (2000) a Elias e Dunning (1992), passando por Caillois (1990), apesar de partirem muitas vezes de premissas distintas, todos estes autores são unânimes em salientar a estreita ligação entre os componentes lúdicos e as forças motrizes das sociedades.

Devemos então trazer à tona as principais características que distinguem o MMA de outros esportes e jogos contemporâneos, assim como as que 
se mantêm constantes. Talvez a característica mais evidente do MMA, a mais gritante, seja a explicitação da violência (para muitos adeptos da modalidade, o termo violência é substituído pelo termo agressividade, já que estes entendem que a violência é algo sem controle, pura liberação de energia, algo não condizente com o esporte, que é regrado e cujos partícipes estão de pleno acordo em entrarem em confronto). A violência, ou agressividade dos combates, onde 0 sangue é um elemento tão presente quanto o suor, ao mesmo tempo em que é 0 aspecto mais polêmico da atividade é também a sua faceta mais atraente e sedutora.

No entanto, o elemento da confrontação, da disputa, o espírito agonístico, não é exclusividade do MMA. Na verdade, basicamente todos os esportes (entendidos como categoria lúdica que possui elementos que a distingue de outras categorias, como as brincadeiras e jogos não competitivos) possuem como elo central de ligação o agôn. Em última instância, todos os esportes são representações mais ou menos metaforizadas de um confronto beligerante, onde as partes envolvidas na contenta, de acordo com regras pré-estabelecidas, dentro de limites prédeterminados, lançam mão de todo 0 seu arsenal para vencer 0 oponente.

Roger Caillois (1990) defende que a passagem da máscara e da vertigem (mimicry e ilinx) como fontes centrais de coesão social para a dupla sorte e disputa (alea e agôn) foi justamente o principal elemento de distinção da passagem das sociedades ditas "primitivas" para a civilização. 0 aspecto agonístico dos jogos, a partir do momento que vai ganhando cada vez mais espaço, é causa e consequência de um maior grau de especialização das atividades, de complexidade dos modos de vida, de uma maior regulação das formas de se viver e da forma de direcionar 0 trabalho desenvolvido nestas sociedades com fins de intervir no mundo, de moldá-lo de acordo com seus interesses.

Huizinga, em muitos momentos de seu livro, evidencia como a noção de jogo - que em muitas línguas de origem indo-europeia não possuíam uma palavra única para designar o jogo enquanto categoria, mas mais de uma, às vezes três ou quatro palavras que ora evidenciavam um aspecto específico de alguma atividade - estava amplamente amparada na competição. Dentre estas separações, a exemplo do que ocorria no grego antigo e no latim, as atividades de caráter competitivo eram muitas vezes tratadas como uma categoria à parte, uma forma de designação que, apesar de não excluir os aspectos da ludicidade, da brincadeira, da fanfarronice, significavam em grande parte a própria civilização.

Dentre as manifestações lúdicas de caráter competitivo, os esportes modernos certamente são as que mais se destacam e que corporificam a essência agonística. 0 surgimento do esporte moderno é tributário de vários movimentos políticos, econômicos e culturais que ressignificaram os antigos jogos, destituindo-os de seu caráter transcendente e trazendo-os para o reino da secularização. A disseminação dos 
esportes enquanto atividade lúdica, amplamente praticada nas sociedades capitalistas contemporâneas, é prenhe dos valores destas mesmas sociedades: é voltado para a obtenção do recorde, para a meta e para sua superação, estabelece uma profícua relação com a ciência, com a busca do aperfeiçoamento dos movimentos corporais, assume a competição e a busca de igualdade de condições (mesmo que num plano ideológico) como fator básico para a ocorrência do jogo, pune 0 desrespeito à regra e exige uma conduta minimamente cortês e respeitosa com 0 adversário, premia 0 esforço e 0 mérito, 0 treinamento e a dedicação etc. (BRACHT, 2003).

No entanto, se podemos amplamente atribuir aos esportes uma vasta aproximação com a estrutura das sociedades contemporâneas, devemos nos atentar para a atual fase de desenvolvimento do capitalismo, não apenas em seus aspectos político-econômicos, mas, sobretudo, nas mudanças que esta nova conjuntura imprime nos padrões culturais dos indivíduos inseridos neste novo contexto, principalmente impulsionados pelo desenvolvimento de novos meios de comunicação.

\section{Mídia, esportes e sociedade}

Tão logo os esportes galgaram um desenvolvimento rumo à sua atual configuração, e assim que as associações desportivas passaram a se proliferar no início do século XVIII não apenas na Inglaterra, mas em toda a Europa, os meios de comunicação disponíveis, na época, logo começaram a prestar atenção a este novo gênero de notícias. Segundo Daniel Bech e Louis Bosshart, os primeiros artigos relacionados aos esportes apareceram no início do século XVIII. Um dos primeiros registros deste gênero é um artigo datado de 1733 e publicado no Boston Gazette que retratava uma luta de boxe disputada entre os atletas John Faulcomer e Bob Russel. Este tipo de material jornalístico era encontrado com certa frequência na seção de notícias locais. Ainda segundo os autores:

0 primeiro jornal com uma seção especial dedicada aos esportes foi Morning Herald, na Inglaterra (1817), seguido por outros jornais Ingleses e Americanos: The Globe (Inglaterra, 1818), The American Farmer (EUA, 1819), e Bell's Life (Inglaterra, 1824, publicado aos dominfos). The Times, o conservador jornal Iondrino, introduziu a sua seção de esportes em 1829. Todas estas seções esportivas continham notícias locais, já que as transmissões telegráficas ainda não estavam disponíveis. ${ }^{1}$ (BECH; BOSSHART, 2003, p. 6, tradução nossa).

Os esportes com maior visibilidade e capilaridade na época eram o boxe, o ciclismo, as corridas de cavalo, o baseball e 0 futebol. Processo semelhante pôde ser observado em terras brasileiras, quando notas sobre a realização de eventos de turfe e seus resultados

Tradução livre. No original: The first newspaper with a special sports section was the Morning Herald in England (1817), followed by other English and American papers: The Globe (England, 1818), The American Farmer (USA, 1819), and Bell's Life (England, 1824, published on Sundays). The Times, the conservative London paper, introduced its sports section in 1829. All these sports sections contained local news, as telegraph transmission was not yet available. 
eram frequentemente publicados nos jornais

cariocas deste início do século XIX (MELO, 2012).

Não buscaremos aqui o resgate histórico da imprensa esportiva, mas sim buscaremos entender qual o papel que os meios de comunicação de massa tiveram na proliferação do esporte moderno. Talvez seja impossível determinar quem foi responsável pelo desenvolvimento destas duas atividades, os esportes e o jornalismo dedicado à cobertura esportiva, assim como sugere Victor de Mello em sua pesquisa historiográfica, se os esportes cresceram por conta da imprensa ou se 0 desenvolvimento de uma imprensa esportiva foi fruto de uma busca e um interesse do público por este tipo de informação.

Enfim, a imprensa esportiva progressivamente noticiou o esporte porque ele crescentemente tornou-se uma prática socialmente valorizada, e a prática também se tornou crescentemente valorizada porque foi progressivamente noticiada na imprensa. Nem só causa, nem só consequência: causa e consequência (MELO, 2012, p. 121).

Aceitando esta simbiose entre 0 desenvolvimento de uma imprensa voltada para a cobertura esportiva e o desenvolvimento do esporte, chegamos a um ponto fundamental de nossa análise, que é a que assume que os esportes contemporâneos não mais podem ser entendidos de forma dissociada dos meios de comunicação. Esta simbiose vai além do simples relato dos fatos esportivos, chegando mesmo a interferir na configuração dos próprios jogos.
Na verdade, os meios de comunicação como fontes mediadoras entre realidades permitem que 0 jogo desenvolva-se para muito além do campo de competição, da arena, ampliando os fatos esportivos de forma exponencial. A grande atenção dada aos jogadores, aos bastidores das competições, aos dirigentes esportivos, aos estádios e à própria torcida mostra como os esportes de forma geral não devem ser entendidos somente enquanto jogos isolados da realidade em que estão inseridos. Cria-se na verdade um circuito de íntima dependência entre estas duas esferas, já que os meios de comunicação são as únicas ferramentas disponíveis para elevar qualquer jogo a um nível de significação que extrapole as barreiras físicas do lócus das competições.

A queda das barreiras territoriais proporcionada pelos meios de comunicação lançou na verdade novas possibilidades de identificação e de sociabilidade, potencializadas de forma que modificaram a própria estrutura dos espetáculos esportivos em geral. Se no início os clubes desportivos cumpriam uma função de amálgama social restrito a pequenos grupos, voltados para interesses específicos de uma determinada classe social ou grupo de aficionados, com os meios de comunicação esta sociabilidade antes mais segmentada é conduzida para outros níveis.

Amplia-se a rede de torcedores, de fãs. 0s campeonatos deixam de lado o bairrismo e ganham monta mundial. Os ídolos do esporte são tornados 
celebridades, cujas vidas e ações dentro e fora de campo tornam-se produtos de interesse por uma gigante parcela de pessoas, servindo muitas vezes de modelo de conduta ou de posição social almejada.

Se devemos reconhecer que este processo de identificação não é de todo novo no campo dos jogos - o reconhecimento dado aos competidores das antigas olimpíadas gregas ou mesmo a idolatria gerada por muitos gladiadores romanos são apenas alguns dos exemplos mais "batidos" -, já que 0 vitorioso no jogo em muito assemelhase ao herói mitológico nos moldes descritos por Campbell (1990), também devemos reconhecer que as mídias geraram novas formas de identificação com este herói, ampliando por uma série de artifícios e recursos a exploração de sua figura.

\section{É o que nos traz Morin (1997) em Cultura de} Massas no século XX, quando busca entender como as figuras icônicas não apenas do esporte, mas do mundo midiático são trabalhadas e consumidas por uma legião de seguidores. Esta busca de identificação com estas celebridades, segundo Morin, deve ser entendida pelo duplo caráter destas pessoas que, se por um lado realizam feitos intangíveis para a grande maioria da população, por outro demonstram a sua humanidade numa série de ações que os impedem de habitar em definitivo um espaço extraterreno.

Um Olimpo de vedetes domina a cultura de massa, mas se comunica, pela cultura de massa, com a humanidade corrente. Os olimpianos, por meio de sua dupla natureza, divina e humana, efetuam a circulação permanente entre 0 mundo da projeção e o mundo da identificação. Concentram nessa dupla natureza um complexo virulento de projeção-identificação. Eles realizam os fantasmas que os mortais não podem realizar, mas chamam os mortais para realizar 0 imaginário. A esse título os olimpianos são os condensadores energéticos da cultura de massa. Sua segunda natureza, por meio da qual cada um se pode comunicar com sua natureza divina, fá-los participar também da vida de cada um. Conjugando a vida quotidiana e a vida olimpiana, os olimpianos tornam modelos de cultura no sentido etnográfico do termo, isto é, modelos de vida. São heróis modelos. Encarnam os mitos de auto-realização da vida privada (MORIN, 1997, p. 107).

Os esportes, assim como o cinema ou a telenovela, fornecem estes modelos de projeção-identificação, ora mostrando uma vida que não pode ser vivida por todos, ora mostrando o que os torna iguais ao resto dos indivíduos.

Sobre este aspecto, é interessante também voltarmos um pouco ao que já expusemos sobre a teoria de Roger Caillois, que aponta o declínio da máscara e da vertigem e a disseminação do mérito e da sorte como as principais características das sociedades complexas. No entanto, apesar de não mais conservar o seu papel central, a mimicry ainda encontra um espaço fundamental para se desenvolver, uma espécie de espaço compensatório para os ditames da dupla agôn-alea. É o mecanismo da delegação, basicamente 0 mesmo processo de projeçãoidentificação defendido por Morin, que permite que os indivíduos "comuns" possam de alguma forma viver, mesmo que por breves momentos ou mesmo de forma caricata a vida de seus ídolos. 
Um mimetismo larvar e benigno fornece uma inofensiva compensação a uma multidão resignada, sem esperança nem propósito firme de ascender ao universo de luxo e de glória que a deslumbra. A mimicry surge difusa e adulterada. Privada da máscara, já não conduz à possessão e à hipnose, mas sim à mais vã das ilusões, a que desponta no fascínio de uma sala escura ou no estádio ensolarado, no momento em que todos os olhares se fixam nos gestos dum luminoso herói. É refletida indefinidamente pela publicidade, pela imprensa e pela rádio. Identifica, de longe, milhares de vítimas paralisadas com os seus ases favoritos. Fá-los viver em imaginação uma vida plena e sumptuosa, cujo quadro e cujos dramas Ihes são diariamente descritos. Embora a máscara já só se use em ocasiões especiais, ou quase se não use, a mimicry, agora infinitamente exposta aos olhos de todos, serve de base ou de contrapeso às novas normas que governam a sociedade (CAILLOIS, 1990, p. 149).

Neste sentido, os meios de comunicação não apenas permitem uma disseminação maior do jogo em si, de determinado esporte ou espetáculo, mas geram um verdadeiro novo mundo que possibilita a inserção e identificação psíquica dos indivíduos com alguns modelos ideais, que logo serão amplamente explorados em todos os sentidos, tanto comercialmente quanto ideologicamente.

As marcas deste belo casamento - cujo divórcio nem passa pela cabeça de seus cônjuges podem ser encontradas desde a publicidade dentro e fora da arena, pelos produtos derivados do jogo (brinquedos, mascotes, jogos eletrônicos que reproduzem o jogo etc), ou mesmo na alteração nos horários das transmissões esportivas para melhor se adequarem aos horários dos grandes veículos de comunicação (BOURDIEU, 1997; MÜLLER, 1996).

As Artes Marciais Mistas já nascem neste contexto matrimonial entre mídia e esporte, sendo pensadas desde o início para inseriremse nele. Se lembrarmos o processo de criação do Ultimate Fighting Championship (UFC) atualmente 0 principal torneio de MMA em todo o mundo - desde a escolha dos lutadores até a concepção do ringue octogonal, lembraremos que inicialmente seu objetivo era muito mais a criação de um produto midiático do que uma disputa esportiva. Obviamente que não devemos excluir a vontade de algumas pessoas em de fato desenvolver as lutas e torná-las "esportivas", assim como fala Rorion $\mathrm{Gracie}^{2}$ sobre seu objetivo principal com o UFC, 0 de disseminar 0 jiu-jitsu brasileiro mundo afora. No entanto, sem todo 0 aparato midiático montado em torno do evento, que foi se rebuscando ao longo do tempo, principalmente após a compra do torneio pela empresa Zuffa, dificilmente veríamos o MMA com a permeabilidade que hoje usufrui.

Ainda nesta toada, além desta simbiose mais nítida, da mútua dependência entre as duas esferas, a esportiva e a midiática, precisamos refletir sobre o papel das mídias em geral para a 
construção de uma sociedade que, grosso modo, podemos chamar de globalizada.

\section{MMA, 0 esporte do capitalismo globalizado}

Podemos dizer aqui, sem nos apegarmos muito à terminologia, mas sim às características do fenômeno, que estamos caminhando a passos largos para a criação de uma virtualidade (entendida aqui no sentido de possibilidade) comunicativa global. Isso quer dizer que, mesmo que queiramos negar, estamos entrando em contato cada vez mais constante com tecnologias de informação e comunicação que nos permitem o reconhecimento da possibilidade de existências e de formas de ser que antes nem sequer eram cogitadas. Vivemos um alargamento da possibilidade de contato entre as culturas. Possibilidade esta que poderá ou não ser efetivada em decorrência de uma série de ajustes finos entre condições de produção material, de acesso às ferramentas, de domínio e reconhecimento da nova dinâmica tecnológico-comunicacional colocada, da imposição das instituições, e mesmo das vontades subjetivas mais arraigadas aos indivíduos e comunidades.

Como nos lembra Armand Mattelart (1994, 2002), essas transformações pelas quais os meios de comunicação passaram para se constituírem tais quais os conhecemos hoje foram um processo fortemente atrelado às ideias imperantes de racionalização e progresso forjadas no iluminismo e levadas a cabo pelos Estados e empresas. 0s meios de comunicação de massa e, mais posteriormente, os meios de comunicação segmentados (se é que podemos concebê-los desta forma), possuem em sua gênese a vontade de expandir, expansão esta que tem na noção de fluxo seu principal sustentáculo. Fluxo de informações e capital, capaz de percorrer todo 0 globo ao mesmo tempo, dando-o uma imagem de totalidade e um relativo controle.

Concordamos com Mattelart no que tange à mundialização da economia, às estruturas do sistema e as forças motrizes da expansão da comunicação; no entanto, resta buscar entender quais são os usos, as práticas e condutas tanto individuais quanto coletivas desencadeadas pelo contato com este novo status quo.

As linhas interpretativas e ideológicas que se ramificam a partir desta constatação - a de uma mundialização da possibilidade de comunicação - são várias, ora pendendo para 0 deslumbre, para a euforia frente ao novo mundo de possibilidades, ora pendendo para evidenciar 0 aumento das desigualdades e a dissolução dos antigos modos de vida, das culturas antes bem delimitadas e estabelecidas, apontando as mazelas do capitalismo globalizante.

Assumiremos aqui que o processo de globalização não é único e homogêneo, mas sim multifacetado. De um lado temos o crescimento dos fluxos de informação e de capitais, de aumento da 
produção e circulação de mercadorias em nível global e, por outro lado, temos também um aumento da concentração de poderes em grandes conglomerados mundiais que aumentam a desigualdade da distribuição desta produção global (HOBSBAWM, 2000).

Deixando um pouco de lado os aspectos econômicos mais evidentes e partindo para uma compreensão da significação e da identidade dos indivíduos e comunidades que são perpassados pela globalização, como nos lembra Stuart Hall (2005), a ampliação das fronteiras sensíveis individuais e coletivas, em linhas gerais, permite a identificação de dois movimentos básicos: a tradição e a tradução. A primeira equivaleria à busca de raízes, à busca de uma identidade anterior à atual configuração da comunidade, buscando num passado glorioso - na maior parte das vezes um passado muito mais fantasioso do que propriamente factível - a ancoragem comunal no mundo. 0 segundo movimento, a tradução, estaria calcada na tentativa de reconhecer o elemento até então "alienígena" e buscar integrá-lo à dinâmica da comunidade, tentando de alguma forma manter as suas particularidades sem, no entanto, impedir a sua "contaminação" com o diferente.

Os esportes em geral, e mais especificamente o MMA, quando inseridos neste novo contexto, permitem amplamente o reconhecimento desta tensão, já que os valores encenados no ringue muitas vezes pendem para um apelo ao tradicional (vale lembrar, por exemplo, que os lutadores são identificados por sua nacionalidade, alguns entram carregando bandeiras de seus países) e ora pendem para a hibridização (retomando a nacionalidade dos lutadores, muitos deles não concedem entrevistas em seu idioma nativo e sim em inglês, língua que atualmente se configura como ponta de lança da comunicação em nível global).

Nesta tensão entre culturas e modos de vida diferentes, quando as barreiras culturais mais estreitas e 0 senso de comunidade fundada na proximidade física são remodelados e deixam de serem as únicas possibilidades, é natural esperarmos que de alguma forma as pessoas e comunidades impelidas a reconhecer esta dimensão maior, "global" busquem simbolizar de diversas maneiras este movimento.

0 MMA, de alguma forma, insere-se culturalmente de forma bastante eficiente enquanto esporte capaz de simbolizar e dialogar com estes novos valores crescentes. Mesmo que a globalização - ou qualquer outro termo adjacente capaz de dar conta deste aumento dos fluxos informacionais e a relativização das barreiras físicas e psíquicas antes bem delimitadas - não seja um processo pleno, igualitário e espontâneo, mas fruto de um projeto de sociedade iluminista de interligação de todo o mundo e da liberalização dos fluxos de informações e capitais, os indivíduos tocados por este processo necessitam de mecanismos e formas de reconhecer este novo cenário e atuar nele. De forma paralela ao processo de 
formação dos esportes modernos observado por Elias e Dunning (1992), que simbolizavam o processo de parlamentarização nas atividades recreativas da elite, o MMA de alguma forma também simboliza este novo contexto das sociedades capitalistas contemporâneas.

Mesmo que ideologicamente e nunca plenamente realizável, a globalização vende uma ideia de distribuição e ocupação igualitária tanto das atividades produtivas quanto das atividades lúdicas. A grande sedução do discurso da globalização, da queda das barreiras e das fronteiras é a de vender a ideia da possibilidade de ação ilimitada pelos indivíduos, a ideia de que estes podem agir e se movimentar livremente pelo mundo, aproveitando agora das "delícias" que cada canto do globo tem a oferecer. Se é verdade que uma ínfima parcela da população mundial de fato usufrui deste lado positivo, tem os meios e, acima de tudo, a permissão para andar de forma desimpedida pelo mundo, os que não fazem parte desta elite global continuam uma vida resignada e obediente aos desmandos desta mesma elite que gerencia de forma estratégica a aplicação dos recursos naturais e humanos em escala global.

Voltamos a insistir que, apesar de as possibilidades oriundas da globalização não serem usufruídas de forma plena por todos, ao menos ao nível ideológico, as pessoas vivem este espírito. Os meios de comunicação ajudam a manter a ilusão da plena possibilidade, da capacidade do indivíduo, da troca livre de informações e da possibilidade empreendedora individual.

Com o fim das disputadas bélicas e ideológicas que direta ou indiretamente dominavam o mundo entre os períodos pós-Segunda Guerra e a dissolução da União Soviética, o que antes era polarização entre os dois blocos, o capitalista e o comunista, agora é vendido como multicultural, como plural.

A ideologia imperante é a de que não mais existem mundos e atitudes a serem moldados, corações e mentes a serem conquistados, mas sim a de se viver plenamente enquanto indivíduo capaz de dialogar com este novo cenário e transitar de forma plena pelas diversas culturas e terrenos, sempre aproveitando as possibilidades que a interligação da comunicação e das mercadorias possam vir a oferecer. Desta forma, pensar o MMA enquanto esporte deve ser pensar, antes de mais nada, os caminhos que esta sociedade globalizada - mesmo que no nível ideológico.

Antes de frutificar, no entanto, o MMA precisou de uma semente que encontrou um solo bastante fértil que permitiu o seu desabrochar. Para atingir a dimensão que possui atualmente, o MMA precisou buscar um território "neutro" para construir seus alicerces, no caso, o território brasileiro, tendo no BJJ (Jiu-Jitsu Brasileiro, em inglês) a sua principal arma e sua principal "história" fundadora.

A arte marcial aprimorada pelos Gracie era extremamente sedutora para esta nova sociedade 
que busca a valorização da hibridização: ela possuía um grande exotismo, era uma arte marcial adormecida para o mundo, uma arte marcial extremamente efetiva e guardada por uns poucos, originada no oriente e preservada no ocidente, mas acima de tudo era uma arte vencedora, destronava as piruetas e os chutes rodados das artes marciais plásticas amplamente exploradas pelo cinema e pelo vídeo-game e subjugava-as. 0 Jiu-jitsu brasileiro era um exemplar a ser enaltecido da possibilidade da mistura cultural que deu certo e foi capaz de vencer a tradição.

0 papel antropofágico realizado pelo BJJ foi fundamental para a aceitação das artes marciais mistas em nível global. 0 MMA majoritariamente o UFC - vende-se não como uma luta que teve suas bases no oriente, como o judô ou o karatê, por exemplo, que trazem junto de si toda uma carga simbólica, um "senso comum" sobre o que são as artes marciais orientais (pautadas pela disciplina, pelo respeito, pelo desenvolvimento pessoal etc.), nem como 0 boxe - exemplo de combate que antes do MMA era o que mais representava o "peso" dos valores ocidentais -, mas sim como uma luta engendrada sob novos matizes, com uma carga simbólica que, se não neutra, era a que mais se aproximava de uma ideia mestiça, híbrida por excelência, permeável, absorvente e criadora.

Soma-se a isto o fato de que, com 0 aumento da dissolução do poder dos Estados e da mudança gradativa na forma de se pensar o mundo, as instituições e as ações coletivas e a acentuação do poder e da liberdade dos indivíduos processo este que chamaremos de pós-moderno - a insegurança que antes tinha causa concreta aparente, o inimigo externo ou interno sempre à espreita, agora torna-se dispersa, sem causas sociais aparentes. 0 peso recai no indivíduo ou em grupo cada vez mais segmentados, as neotribos (MAFFESOLI, 2005). Daí, segundo Bauman, grande parte da violência pós-moderna pode ser explicada desta forma, pela busca da reafirmação individual e grupal por meio da solidificação de sua imagem. Aceita-se e valorizase a violência, o aumento do impacto como forma legítima, na verdade a única capaz de fazer o indivíduo mostrar-se e ser reconhecido. Ampliaremos este posicionamento buscando paralelos com o crescimento do MMA.

A recoletivização da violência no serviço da autoafirmação neotribal é apenas um dos resultados da privatização pós-moderna dos problemas de identidade. 0 outro é a tendência a mobilizar formas de violência gradualmente "normalizadas", legalmente permitidas e culturalmente aprovadas no processo de autoafirmação individual. Este é agora cada vez mais orientado pela busca de flexibilidade e permanente abertura de opções, pelo ressentimento de se estar vinculado às necessidades dos outros e pela relutância em se aceitar uma inconveniência que não traz nenhum benefício visível para a satisfação dos prazeres de alguém (BAUMAN, 2011a, p. 215).

Se num contexto moderno, num Estado ou numa sociedade com propósitos e "missões" relativamente bem estabelecidos, com instituições fortes capazes de manter a coesão interna a 
identificação coletiva e a ação individual eram mais fáceis, num contexto pós-moderno de relativização de enfraquecimento (para não dizer queda) dos modelos consagrados de organização social e de distribuição dos papéis sociais, são os pequenos grupos de interesse e os indivíduos que devem agora lidar com o mundo e com os outros da melhor forma possível. Se nas sociedades modernas clássicas 0 papel social a ser cumprido pelos indivíduos era claro - assim como era claro o desviante, 0 incapacitado e o degenerado, nas sociedades pós-modernas, a moral é muito mais relativista, ao menos ideologicamente, 0 "faça você mesmo", "seja você mesmo", "viva intensamente" são as palavras de ordem que vem substituir as antigas "abaixo a ditadura", "a burguesia fede" e tantas outras.

Esta nova forma de sensibilidade e de restruturação social, como já dissemos, evidentemente deverá ser levada em conta para a busca de explicações plausíveis que justifiquem cada vez mais uma busca e aceitação dos indivíduos pelas lutas de MMA.

A nossa é a primeira cultura na história a não premiar a duração e a conseguir fatiar o tempo de vida em séries de episódios vividos com a intenção de protelar suas consequências duradouras e evitar compromissos firmes que tornariam tais consequências restritivas. A eternidade não importa, a não ser para a experiência instantânea. 0 'longo prazo' é apenas um pacote de Erlebnisse de curto prazo, receptivo a um incessante embaralhamento e sem uma ordem privilegiada de sucessão. 0 infinito foi reduzido a uma série de 'aqui e agora'; a imortalidade, à interminável reciclagem de nascimentos e mortes (BAUMAN, 2009, p. 313).
0 refluxo das grandes narrativas totalizadoras abre espaço para a ascensão de novas narrativas, mais adequadas ao novo contexto das sociedades capitalistas contemporâneas. Não é de se estranhar que 0 surgimento e a busca por novos jogos, por novos esportes, ganhe tanta importância. 0 MMA, dessa maneira, pode ser encarado como um novo espaço narrativo da modernidade líquida (ou pós-Modernidade). A reciclagem de nascimentos e mortes sugerida por Bauman é metaforizada nas lutas, que acontecem uma após a outra, cada uma encerrando em si uma narrativa, um desfecho, que culmina com a vitória de um e derrota de outro, metáfora plena da relação vida e morte. A própria dinâmica do MMA, principalmente 0 UFC, de não possuir uma tabela de pontuação - ele não segue, por exemplo, a mesma lógica de um campeonato de futebol - está em plena sintonia com este "espírito". Uma noite do evento, que engloba aproximadamente 10 lutas, cria uma concatenação de narrativas que, apesar de dentro de uma narrativa maior - a noite do evento - raramente tecem conexões profundas umas com as outras: cada luta é uma narrativa, cada luta encerra um mundo em si mesmo. A própria escolha dos lutadores que compõem o card (relação das lutas do evento) é feita de forma subjetiva, não seguindo um sistema racional de pontuação. 0s dirigentes e empresários do evento são quem combinam as lutas e, para tanto, seguem motivações que muitas vezes não são explícitas e tangíveis a todos os que acompanham o esporte. 
Entretanto, apesar de 0 espectador deste esporte/ espetáculo não poder acompanhar de antemão a "escalação" das lutas, tal configuração talvez seja justamente uma explicação e um "sintoma" dessa nova dinâmica social. Tal lógica exige menos esforço, exige uma menor doação e participação do "eu" na constituição de uma macro-narrativa (retomando o exemplo do futebol, geralmente podemos dizer que 0 torcedor deve acompanhar todas as partidas de um campeonato, já que 0 resultado da partida anterior geralmente influencia na partida futura a ser jogada e, muitas vezes o resultado dos jogos de outros times também influi na classificação), liberando-o para a fruição momento a momento, um momento breve que será rapidamente substituído por outro. A lógica da adesão-distensão constantes na busca do máximo de gozo no menor espaço de tempo possível é a que impera.

Não queremos com isso decretar o fim das grandes narrativas, mas sim demonstrar 0 surgimento de uma nova dinâmica social que corre em paralelo à antiga. Falamos aqui do reino da ambiguidade e, portanto, apenas buscamos sugerir uma possibilidade de abordagem do fenômeno estudado.

A argumentação tecida, até agora, vai no sentido de buscar compreender a atividade para além de seu aspecto mais rapidamente depreendido, a questão da luta, da violência, e sim na direção de buscar entender que este elemento agonístico tem muito mais a dizer sobre uma nova cultura emergente do que o simples jorrar do sangue. A linguagem da luta, entendida como linguagem do corpo em movimento, é tão antiga quanto a humanidade e, dessa forma, a compreensão de suas premissas é tão facilmente reconhecida por culturas diversas que ela torna-se um "curinga" por excelência desta nova comunidade que cada vez mais reconhece sua "capacidade global".

Apesar do caráter ancestral da atividade lúdica da luta, não podemos nos esquecer de que 0 formato que conhecemos hoje como MMA passou por uma série de "filtros" e restrições com o objetivo de modelar-se aos valores normativos das sociedades capitalistas contemporâneas.

A atividade do MMA possui esta múltipla faceta: por um lado, enquanto atividade física, é uma das que mais se aproxima da liberdade lúdica (vale lembrar que 0 espírito agonístico é uma das principais características de qualquer tipo jogo), é de fácil compreensão perante uma comunidade global e, por outro lado, as suas características também evidenciam um projeto de sociedade no qual a atividade se insere. Um projeto de sociedade pautado pelo desenvolvimento da lucratividade, do progresso linear e exponencial, do livre e veloz fluxo de informações e capitais e da ampliação do consumo em todos os níveis, tanto material quanto simbólico.

Ao mesmo tempo em que é uma atividade "aberta", o MMA é também amplamente contaminado (na verdade, como esporte/espetáculo ele já nasce com essa proposta) pelo American Way of Life, pela ideia do self-made man, pela ideia da distensão 
máxima das regras (livre mercado, por exemplo) e do empreendedorismo, com a noção de que todos possuem as mesmas condições e, assim, que vença o melhor (darwinismo social).

\section{Considerações finais}

0 presente artigo teve como objetivo traçar algumas linhas analíticas que podem ser derivadas do estudo dos esportes e jogos, especificamente apresentando algumas das principais características que acreditamos serem as mais prementes para a compreensão do surgimento e da penetração que o MMA goza atualmente.

Longe dos antigos estereótipos e preconceitos acadêmicos que por muito tempo imperaram em relação ao estudo dos esportes, este estudo - assim como uma rica produção que ganha monta não apenas nacionalmente, mas em nível internacional - insere-se nesta nova tendência de valorização dos objetos de estudo que até outrora foram desprezados, acentuando a importância e a riqueza que o debate acerca do tema nos tem a oferecer para uma compreensão mais profunda e plural sobre as relações do homem consigo mesmo e com o seu entorno.

\section{Referências}

BAUMAN, Zygmunt. A sociedade individualizada: vidas contadas e histórias vividas. Rio de Janeiro: Zahar, 2009.

BAUMAN, Zygmunt. Vida em fragmentos: sobre a ética pós-moderna. Rio de Janeiro: Zahar, 2011a.
BAUMAN, Zygmunt. 44 cartas do mundo líquido moderno. Rio de Janeiro: Zahar, 2011b.

BECH, Daniel; BOSSHART, Louis. Sports and Media. Communication Research Trends, v. 22, n. 4, 2003. Disponível em: < http://cscc.scu.edu/trends/v22/v22_4. pdf > ; acesso em: 17 maio 2012.

BOURDIEU, Pierre. Coisa ditas. São Paulo: Brasiliense, 1990.

BOURDIEU, Pierre. Sobre a televisão. Rio de Janeiro: Jorge Zahar, 1997.

BRACHT, Valter. Sociologia crítica do esporte: uma introdução. Ijuí: Unijuí, 2003

BUDOKAN, Nippon. (Ed.). Budô: The Martial Ways of Japan. Tokyo: Nippon Budokan Foundation: 2009.

CAILLOIS, Roger. Os jogos e os homens. Lisboa: Cotovia, 1990.

CAMPBELL, Joseph, com Bill Moyers. 0 poder do mito. São Paulo: Palas Athena, 1990.

ELIAS, Norbert; DUNNING, Eric. Deporte y ocio en el proceso de la civilización. México, D.F: Fondo de Cultura Económica, 1992.

HALL, S. A identidade cultural da pós-modernidade. Rio de Janeiro: DP\&A, 2005.

HOBSBAWM, E. J. 0 novo século. São Paulo: Companhia das Letras, 2000.

HUIZINGA, J. Homo ludens. São Paulo: Perspectiva, 2000.

MAFFESOLI, M. 0 mistério da conjunção: ensaios sobre comunicação, corpo e socialidade. Porto Alegre: Sulina, 2005.

MATTELART, A. Comunicação mundo: história das idéias e das estratégias. Petrópolis, RJ: Vozes, 1994. A globalização da comunicação. 2.ed. Bauru: Edusc, 2002.

MELO, V. A. de. Causa e consequência: esporte e 
imprensa no Rio de Janeiro do século XIX e década inicial do século XX. In: MARQUES, J. C.; MORAIS, 0. J. (Org.). Esportes na Idade Mídia: diversão, informação e educação. São Paulo: INTERCOM, 2012. p. 103-124.

MORIN, E. Cultura de massas no século XX: 0

espírito do tempo, I: neurose. Rio de Janeiro: Forense Universitária, 1997.

MÜLLER, Uwe. Esporte e mídia: um pequeno esboço.

Revista Brasileira de Ciências do Esporte, Curitiba, v. 17, n. 3, 1996. Disponível em: < http://rbceonline. org.br/revista/index.php/RBCE/article/view/849/503>. Acesso em: 22 ago. 2012. 


\section{From Marginality to Mainstream: Reflections on MMA (Mixed Martial Arts) and Contemporary Capitalist Societies}

\section{Abstract}

Our main goal in this paper is to discuss the deep relationship between the main characteristics of contemporary capitalist societies and one of the sports/shows that reaches a bigger number of people not only through the Brazilian media, but also through the international one: MMA, Mixed Martial Arts. Way beyond the most readily identifiable aspects - violence and aggressiveness - this sport/show is paradigmatic, because it embodies a huge amount of politics, economics and cultural aspects that are highly valued in the contemporary development stage of capitalist societies, characterized mainly by the expansion of the flow of information and goods globally, driven especially by the new communication technologies.

\section{Keywords}

Sports. Communication. MMA. Globalization.
De la marginalización al mainstream: reflexiones acerca de MMA (Artes Marciales Mistas) y las sociedades capitalistas contemporáneas

\section{Resumen}

En este artículo intentaremos discutir la íntima relación entre las principales características de las sociedades capitalistas contemporáneas e uno de los deportes/espectáculos que alcanza un gran espacio no apenas en los medios de comunicación de Brasil, sino que en los medios internacionales: el MMA (siglas en inglés para Artes Marciales Mistas). Para mucho adelante de suyo aspecto más prontamente identificable - la violencia 0 agresividad -, este deporte/espectáculo es bastante paradigmático, pues encarna una serie de valores políticos, económicos y culturales ampliamente valorizados en el presente fases de desarrollo de las sociedades capitalistas, caracterizadas mayoritariamente por la expansión de los flujos de información y mercancías en el nivel global, impulsados principalmente por el desarrollo de novas tecnologías de comunicación.

\section{Palabras-Clave}

Deportes. Comunicación. MMA. Globalización. 


\section{Expediente}

A revista E-Compós é a publicação científica em formato eletrônico da Associação Nacional dos Programas de Pós-Graduação em Comunicação (Compós). Lançada em 2004, tem como principal finalidade difundir a produção acadêmica de pesquisadores da área de Comunicação, inseridos em instituições do Brasil e do exterior.

\section{E-COMPÓS I www.e-compos.org.br I E-ISSN 1808-2599}

Revista da Associação Nacional dos Programas

de Pós-Graduação em Comunicacão.

Brasília, v.16, n.3, set./dez. 2013

A identificação das edições, a partir de 2008

passa a ser volume anual com três números.

\section{CONSELHO EDITORIAL}

Afonso Albuquerque, Universidade Federal Fluminense, Brasil Alberto Carlos Augusto Klein, Universidade Estadual de Londrina, Brasil Alex Fernando Teixeira Primo, Universidade Federal do Rio Grande do Sul, Brasil Ana Carolina Damboriarena Escosteguy, Pontifícia Universidade Católica do Rio Grande do Sul, Brasi

Ana Gruszynski, Universidade Federal do Rio Grande do Sul, Brasil Ana Silvia Lopes Davi Médola, Universidade Estadual Paulista, Brasil André Luiz Martins Lemos, Universidade Federal da Bahia, Brasil Ângela Freire Prysthon, Universidade Federal de Pernambuco, Brasil Antônio Fausto Neto, Universidade do Vale do Rio dos Sinos, Brasil Antonio Carlos Hohlfeldt, Pontifícia Universidade Católica do Rio Grande do Sul, Brasil Antonio Roberto Chiachiri Filho, Faculdade Cásper Líbero, Brasil Arlindo Ribeiro Machado, Universidade de São Paulo, Brasil Arthur Autran Franco de Sá Neto, Universidade Federal de São Carlos, Brasil Benjamim Picado, Universidade Federal Fluminense, Brasil César Geraldo Guimarães, Universidade Federal de Minas Gerais, Brasil Cristiane Freitas Gutfreind, Pontifícia Universidade Católica do Rio Grande do Sul, Brasil Denilson Lopes, Universidade Federal do Rio de Janeiro, Brasi Denize Correa Araujo, Universidade Tuiuti do Paraná, Brasi Edilson Cazeloto, Universidade Paulista , Brasil

Eduardo Peñuela Cañizal, Universidade Paulista, Brasil

Eduardo Vicente, Universidade de São Paulo, Brasi

Eneus Trindade, Universidade de São Paulo, Brasi

Erick Felinto de Oliveira, Universidade do Estado do Rio de Janeiro, Brasi

Florence Dravet, Universidade Católica de Brasília, Brasi

Francisco Eduardo Menezes Martins, Universidade Tuiuti do Paraná, Brasil

Gelson Santana, Universidade Anhembi/Morumbi, Brasi

Gilson Vieira Monteiro, Universidade Federal do Amazonas, Brasil

Gislene da Silva, Universidade Federal de Santa Catarina, Brasil

Guillermo Orozco Gómez, Universidad de Guadalajara

Gustavo Daudt Fischer, Universidade do Vale do Rio dos Sinos, Brasil Hector 0spina, Universidad de Manizales, Colômbia

Herom Vargas, Universidade Municipal de São Caetano do Sul, Brasi leda Tucherman, Universidade Federal do Rio de Janeiro, Brasil

Inês Vitorino, Universidade Federal do Ceará, Brasil

Janice Caiafa, Universidade Federal do Rio de Janeiro, Brasil

Jay David Bolter, Georgia Institute of Technology

Jeder Silveira Janotti Junior, Universidade Federal de Pernambuco, Brasi João Freire Filho, Universidade Federal do Rio de Janeiro, Brasil
John DH Downing, University of Texas at Austin, Estados Unidos

José Afonso da Silva Junior, Universidade Federal de Pernambuco, Brasi José Carlos Rodrigues, Pontifícia Universidade Católica do Rio de Janeiro, Brasil José Luiz Aidar Prado, Pontifícia Universidade Católica de São Paulo, Brasil José Luiz Warren Jardim Gomes Braga, Universidade do Vale do Rio dos Sinos, Brasil Juremir Machado da Silva, Pontifícia Universidade Católica do Rio Grande do Sul, Brasil Laan Mendes Barros, Universidade Metodista de São Paulo, Brasi Lance Strate, Fordham University, USA, Estados Unidos Lorraine Leu, University of Bristol, Grã-Bretanha Lucia Leão, Pontifícia Universidade Católica de São Paulo, Brasil Luciana Panke, Universidade Federal do Paraná, Brasil Luiz Claudio Martino, Universidade de Brasília, Brasi Malena Segura Contrera, Universidade Paulista, Brasil

Márcio de Vasconcellos Serelle, Pontifícia Universidade Católica de Minas Gerais, Brasil Maria Aparecida Baccega, Universidade de São Paulo e Escola Superior de Propaganda e Marketing, Brasi

Maria das Graças Pinto Coelho, Universidade Federal do Rio Grande do Norte, Brasil Maria Immacolata Vassallo de Lopes, Universidade de São Paulo, Brasil Maria Luiza Martins de Mendonça, Universidade Federal de Goiás, Brasil Mauro de Souza Ventura, Universidade Estadual Paulista, Brasil

Mauro Pereira Porto, Tulane University, Estados Unidos

Nilda Aparecida Jacks, Universidade Federal do Rio Grande do Sul, Brasi Paulo Roberto Gibaldi Vaz, Universidade Federal do Rio de Janeiro, Brasi Potiguara Mendes Silveira Jr, Universidade Federal de Juiz de Fora, Brasi Renato Cordeiro Gomes, Pontifícia Universidade Católica do Rio de Janeiro, Brasil Robert K Logan, University of Toronto, Canadá Ronaldo George Helal, Universidade do Estado do Rio de Janeiro, Brasil Rosana de Lima Soares, Universidade de São Paulo, Brasi Rose Melo Rocha, Escola Superior de Propaganda e Marketing, Brasil Rossana Reguillo, Instituto de Estudos Superiores do Ocidente, Mexico Rousiley Celi Moreira Maia, Universidade Federal de Minas Gerais, Brasi Sebastião Carlos de Morais Squirra, Universidade Metodista de São Paulo, Brasil Sebastião Guilherme Albano da Costa, Universidade Federal do Rio Grande do Norte, Brasil

Simone Maria Andrade Pereira de Sá, Universidade Federal Fluminense, Brasi Tiago Quiroga Fausto Neto, Universidade de Brasília, Brasil Suzete Venturelli, Universidade de Brasília, Brasil Valerio Fuenzalida Fernández, Puc-Chile, Chile

Veneza Mayora Ronsini, Universidade Federal de Santa Maria, Brasi Vera Regina Veiga França, Universidade Federal de Minas Gerais, Brasil

COMISSÃO EDITORIAL

Adriana Braga I Pontifícia Universidade Católica do Rio de Janeiro, Brasil

CONSULTORES AD HOC

Adriana Amaral, Universidade do Vale do Rio dos Sinos, Brasil

Alexandre Rocha da Silva, Universidade Federal do Rio Grande do Sul, Brasi

Arthur Ituassu, Pontifícia Universidade Católica do Rio de Janeiro, Brasil

Bruno Souza Leal, Universidade Federal de Minas Gerais, Brasil

Elizabeth Bastos Duarte, Universidade Federal de Santa Maria, Brasil

Francisco Paulo Jamil Marques, Universidade Federal do Ceará, Brasi

Maurício Lissovsky, Universidade Federal do Rio de Janeiro, Brasi

Suzana Kilpp, Universidade do Vale do Rio dos Sinos, Brasil

Vander Casaqui, Escola Superior de Propaganda e Marketing, Brasil

EDIÇÃO DE TEXTO E RESUMOS I Susane Barros

SECRETÁRIA EXECUTIVA I Juliana Depiné

EDITORAÇÃO ELETRÔNICA I Roka Estúdio

TRADUÇÃ̃o I Sieni Campos
COMPÓS I www.compos.org.br

Associação Nacional dos Programas de Pós-Graduação em Comunicação

Presidente

Eduardo Morettin

Universidade de São Paulo, Brasil

eduardomorettin@usp.br

Vice-presidente

Inês Vitorino

ines@ufc.br

Secretária-Geral

Gislene da Silva

Universidade Federal de Santa Catarina, Brasi

gislenedasilva@gmail.com
Universidade Federal do Ceará, Brasil 